\title{
Hyperpigmented lichenoid mycosis fungoides as a new variant: clinical and histopathological evaluation
}

\author{
Khalifa E. Sharquie', Fatema A. Al-Jaralla², Adil R. Al-Saadawi ${ }^{3}$ \\ ${ }^{1}$ Department of Dermatology, College of Medicine, University of Baghdad, Iraqi and Arab Board for Dermatology \&
Venereology, Baghdad Teaching Hospital, Medical City, Baghdad, Iraq, ${ }^{2}$ Department of Dermatology, College of Medicine,
University of Baghdad, Baghdad, Iraq, ${ }^{3}$ Department of Pathology, Baghdad Medical City Complex, Baghdad, Iraq
}

Corresponding author: Dr. Fatema A. Al-Jaralla, E-mail: fatema.hamad@yahoo.com

\begin{abstract}
Background: Hyperpigmented (lichenoid) form is a rare subtype of mycosis fungoides which presents with multiple pigmented macules and patches and characterized by a CD8 + phenotype on immunohistochemistry. Up to our knowledge, only limited cases of hyperpigmented MF have been reported so far. Objective: To study the clinical, histopathological, and immunohistochemical features of hyperpigmented lichenoid MF. Patients and methods: Patients with lichenoid MF who had attended department of dermatology, college of medicine, university of Baghdad, Baghdad teaching hospital during the period from 2006 through 2019, were collected. Results: Twelve patients, comprising around $11 \%$ of the patients seen with MF, had hyperpigmented lichenoid patches and plaques. Six patients presented with hyperpigmented patches as the only manifestation of MF. Five patients were presented with poikilodermatous patches in addition to areas of hyperpigmented lesions, and (poikilodermatous patches with ulceration in one patient). One patient had classic MF lesions in association with hyperpigmented MF. On histopathological study, atypical lymphocytes were noticed in the epidermis, with minimal spongiosis, and also at the dermoepidermal junction, causing focal damage. The striking feature was the large numbers of melanophages in the dermis. Conclusion: Hyperpigmented lesions of MF may be the sole manifestation or may coexist with other MF variants. The striking histopathological finding was mainly dermal melanosis. Other hyperpigmented dermatoses like lifa disease might be confused with pigmented MF. Early diagnosis and proper therapy might prevent the progression leading to full recovery.
\end{abstract}

Key words: Hyperpigmented; Lichenoid; Mycosis fungoides; Lifa disease

\section{INTRODUCTION}

Mycosis fungoides (MF) comprise less than $1 \%$ of the total number of non-Hodgkin lymphomas; however, it is the most common cutaneous lymphoma. It usually has an indolent course and good prognosis when identified in its early stages [1]. Classic mycosis fungoides presents with 3 stages: patch (atrophic or nonatrophic), plaque, and tumor. Often, the first stage goes on for many years and might present with nonspecific dermatitis or poikeloderma like, which usually consists of patches and is often found on the lower trunk and buttocks [2]. In addition from the classic patch/plaque type of $\mathrm{MF}$, several variants have been described in the literature, such as follicular, hypopigmented, and ichthyosiform MF [3]. Also, MF may present with numerous forms that might look like benign skin conditions, these may include eczema, folliculitis, pigmented purpuric dermatoses, psoriasis,vitiligo, pityriasis lichenoides chronica, and pityriasis lichenoides et varioliformis acuta. Therefore, clinicopathologic correlation is mandatory to reach a proper diagnosis in the early stages of the disease [4]. Up to the best of our knowledge, there have been a total of nine published reports since 1996, those reports are of 16 patients ( 9 males and 7 females) in which MF was presented entirely or predominantly by hyperpigmented patches or plaques [5-14]. Their ages ranged from 19-69 yr with a mean age of 44 years (Table 1). They were of Fitzpatrick skin type III and IV.

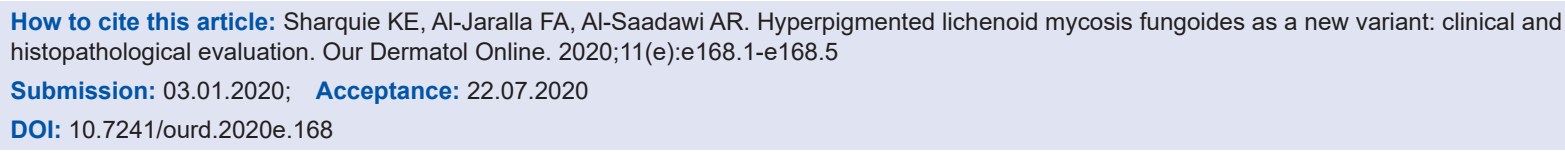


Table 1: Summarizes the clinical data of 16 patients with hyperpigmented mycosis fungoides previously reported

\begin{tabular}{|c|c|c|c|}
\hline Patient no. & Patient age $(y) /$ Sex & Clinical presentation & Source report \\
\hline 1 & $57 / \mathrm{M}$ & $\begin{array}{l}\text { Irregularly shaped itchy annular erythema with central pigmentation predominantly on his } \\
\text { extremities }\end{array}$ & Ref. 5 \\
\hline 2 & $42 / \mathrm{M}$ & $\begin{array}{l}\text { Stage IB misdiagnosed as ashy dermatosis and chronic eczema with disease duration of } 10 \\
\text { years without progression to tumoural stage }\end{array}$ & Ref. 6 \\
\hline 3 & $52 / \mathrm{M}$ & $\begin{array}{l}\text { Pruritic, hyperpigmented macules, some of them became confluent and lichenified } \\
\text { hyperpigmented plaques on the trunk and extremities }\end{array}$ & Ref. 7 \\
\hline 4 & $19 / F$ & Hyperpigmented patches, purpura & Ref. 8 \\
\hline 5 & $33 / F$ & Hyperpigmented patches & \\
\hline 6 & 28/F & Hyperpigmented patches & \\
\hline 7 & $52 / \mathrm{M}$ & Hyperpigmented patches & \\
\hline 8 & $45 / M$ & Hyperpigmented patches, poikiloderma & \\
\hline 9 & 33/M & $\begin{array}{l}\text { Hyperpigmented patches/flat plaques, hypopigmented patches, flat ichthyosiform plaques, } \\
\text { poikiloderma }\end{array}$ & \\
\hline 10 & $69 / F$ & Hyperpigmented patches/flat plaques & \\
\hline 11 & $64 / \mathrm{M}$ & Hyperpigmented patches & \\
\hline 12 & $60 / F$ & Asymptomatic hyperpigmented non- infiltrated plaques on the face & Ref. 9 \\
\hline 13 & $45 / F$ & $\begin{array}{l}\text { Hyperpigmented patches to plaques over the chest, abdomen, back and extremities. Two } \\
\text { adjoining ulcers, measuring } 6 \mathrm{~cm} \text { in diameter were present over the abdomen diagnosed as } \\
\text { ecthyma gangrenosum }\end{array}$ & Ref. 10 \\
\hline 14 & $67 / \mathrm{M}$ & Generalized hyperpigmented patches and plaques all over the body & Ref. 11 \\
\hline 15 & $62 / F$ & Hyperpigmented macules and patches on the trunk and right leg & Ref. 12 \\
\hline 16 & $34 / \mathrm{M}$ & Hyperpigmented patch on the left side of the lower back with slight erythema around it. & Ref. 13 \\
\hline 17 & $29 / F$ & $\begin{array}{l}\text { Exfoliative dermatitis involving about } 50 \% \text { of the skin surface with skin locally thickened and } \\
\text { swollen (on arms) and hyperpignemted }\end{array}$ & Ref. 14 \\
\hline
\end{tabular}

The histopathology of these reported cases mainly showed interface changes, prominent epidermotropism and atypical lymphocytes (small to medium-sized hyperchromatic indented nuclei) aligning along the basal layer and perivascular space with various amounts of melanophages in the dermis. Most cases immunochemistry showed atypical lymphocytes positive for CD3 and CD8 but negative for CD4,CD7, CD20.

Due to the diversity of clinical presentations of early MF; MF can pose a diagnostic challenge to the dermatologists. Reaching a diagnosis for classic MF requires a combination of clinical presentation, histopathology, and immunohistochemistry.

The aim of this study is to take a close look at the clinical, histopathological, and immunohistochemical features of hyperpigmented lichenoid MF and to shed further light on this relatively new and rare variant.

\section{Patients and Methods}

This is an observational study that was conducted in department of dermatology, college of medicine, university of Baghdad, Baghdad teaching hospital during the period from 2006 through 2019; twelve patients with lichenoid MF were presented with multiple pigmented macules and patches. All patients were diagnosed based on results of histopathology, immunohistochemistry and clinical examination according to TNMB WHO classification updated in 2016. Laboratory tests were carried out in all patients, including blood cell-count, blood levels of creatinine, urea, liver enzymes, and lactate dehydrogenase (LDH).

\section{Ethics Statement}

A verbal consent was taken from all patients after full explanation of the study nature and ethical approval was obtained from the Scientific Council of Dermatology and Venereology-Iraqi Board for medical specialization.

\section{RESULTS}

Twelve patients, comprising around $11 \%$ of the patients seen with MF, had hyperpigmented lichenoid patches and plaques (Table 2).

Their ages ranged between 24 and 70 years with a mean of 47 years with 9 males patients and 3 females with a male to female ratio of $3: 1$. The interval from disease onset to diagnosis ranged from 6 to 10 years with a mean of 8 years. All patients had hyperpigmented patches and/or plaques, with various degrees of scaling while 4 patients presented with itching versus eight cases were asymptomatic. All patients were dark-complexioned with Fitzpatrick skin type III and IV. Other causes of hyperpigmentation were excluded before final diagnosis. Six patients presented with hyperpigmented patches as 
Table 2: The clinical data of 12 patients with hyperpigmented lichenoid mycosis fungoides

\begin{tabular}{|c|c|c|c|}
\hline Patient no. & $\begin{array}{l}\text { Patient age }(y) / \text { Sex at } \\
\text { time of presentation }\end{array}$ & Clinical presentation and distribution of lesions & $\begin{array}{l}\text { Staging at } \\
\text { diagnosis }\end{array}$ \\
\hline 1 & $45 / \mathrm{M}$ & $\begin{array}{l}\text { Hyperpigmented scaly patches with poikeloderma involving face, trunk, upper and } \\
\text { lower extremities }\end{array}$ & Stage IB \\
\hline 2 & 40/M & Hyperpigmented patches associated with poikeloderma involving the trunk & Stage IA \\
\hline 3 & $35 / \mathrm{M}$ & $\begin{array}{l}\text { Lichenoid lesions associated with classic MF involving face, trunk, upper and lower } \\
\text { extremities }\end{array}$ & Stage IB \\
\hline 4 & $60 / \mathrm{M}$ & $\begin{array}{l}\text { Lichenoid without poikelodermatous lesions involving face, trunk, upper and lower } \\
\text { extremities }\end{array}$ & Stage IB \\
\hline 5 & $62 / F$ & $\begin{array}{l}\text { Hyperpigmented patches without poikelodermatous lesions involving face, trunk, } \\
\text { upper and lower extremities }\end{array}$ & Stage IB \\
\hline 6 & 70/M & Lichenoid associated with poikeloderma involving trunk and face & Stage IIB \\
\hline 7 & $50 / F$ & $\begin{array}{l}\text { Hyperpigmented patches associated with poikeloderma involving trunk, upper and } \\
\text { lower extremities }\end{array}$ & Stage IB \\
\hline 8 & $56 / \mathrm{M}$ & $\begin{array}{l}\text { Lichenoid without poikelodermatous lesions/ ulcerated involving face, trunk, upper } \\
\text { and lower extremities }\end{array}$ & Stage IIB \\
\hline 9 & 24/M & Lichenoid plaque without poikelodermatous lesions/ single lesion on the trunk & Stage IA \\
\hline 10 & $36 / F$ & $\begin{array}{l}\text { Pruritic hyperpigmented patches without poikelodermatous lesions involving face, } \\
\text { trunk, upper and lower extremities }\end{array}$ & Stage IB \\
\hline 11 & $27 / M$ & $\begin{array}{l}\text { Hyperpigmented patches without poikelodermatous lesions involving face, trunk, } \\
\text { upper and lower extremities }\end{array}$ & Stage IB \\
\hline 12 & $60 / \mathrm{M}$ & $\begin{array}{l}\text { Lichenoid without poikelodermatous lesions involving face, trunk, upper and lower } \\
\text { extremities }\end{array}$ & Stage IB \\
\hline
\end{tabular}

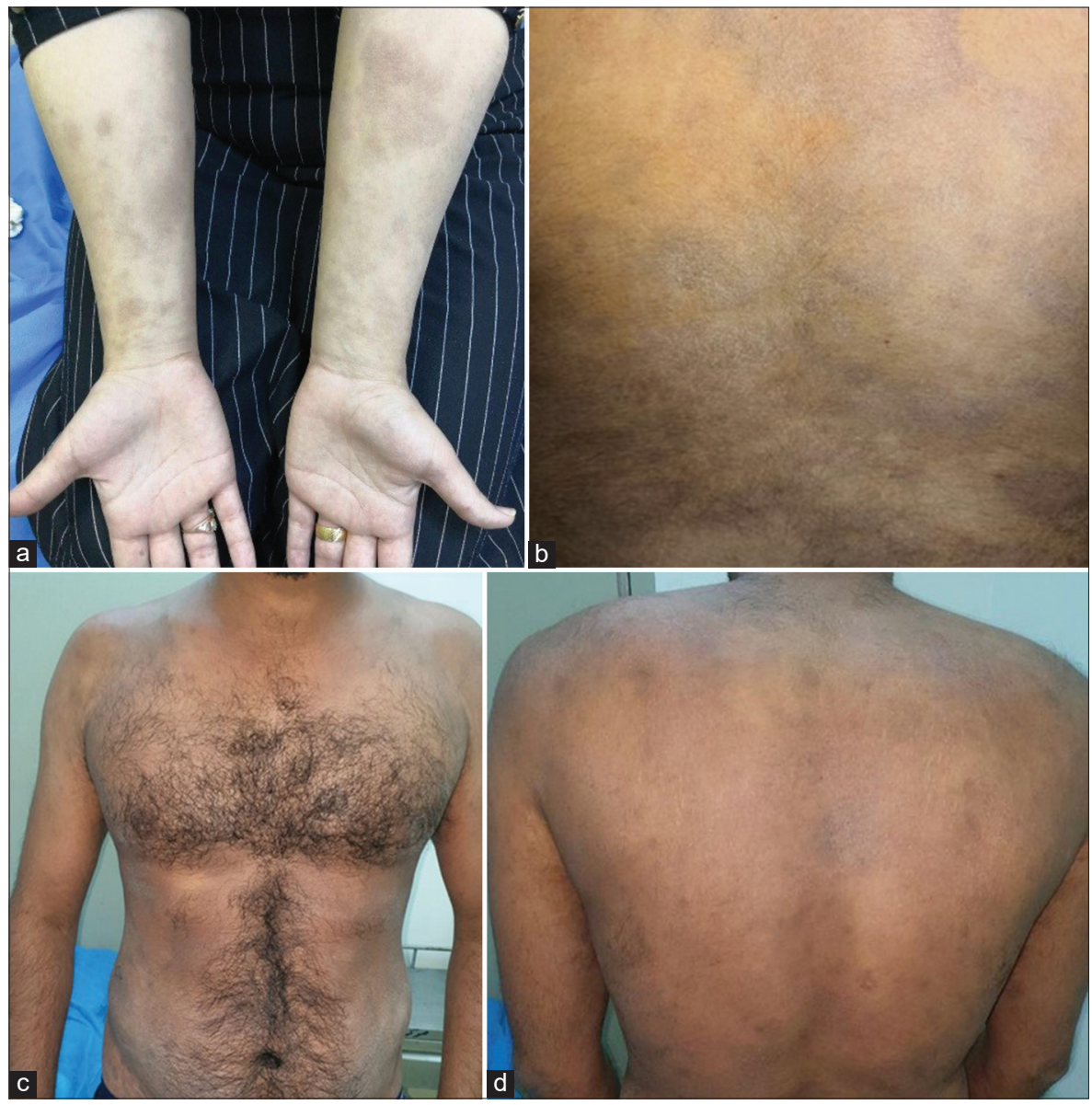

Figure 1: 36-year-old female ( $a$ and $b)$ and 27 year old male ( $c$ and $d)$ both presented with itchy hyper pigmented patches as the only manifestation of mycosis fungoides.

the only manifestation of MF (Figs. la - ld). However, five patients were seen with poikilodermatous patches in addition to areas of hyperpigmented lesions, and (poikilodermatous with ulceration in one patient) 
(Figs. 2a and 2b). While one patient had classic MF lesions in association with hyperpigmented MF.

On histopathological study, there was acanthosis of epidermis with some areas of atrophy with lymphpcytic invasion. Also liquefaction degeneration of the basal layer was noticed. There was a varying degrees of superficial and deep perivascular lymphocytic infiltration of dermis. But the striking feature was the large numbers of melanophages in the dermis (Figs. 3a and 3b).

Immunohistochemical studies were done for two patients only due to unavailability of the test, one of the patients showed positive staining for CD3,

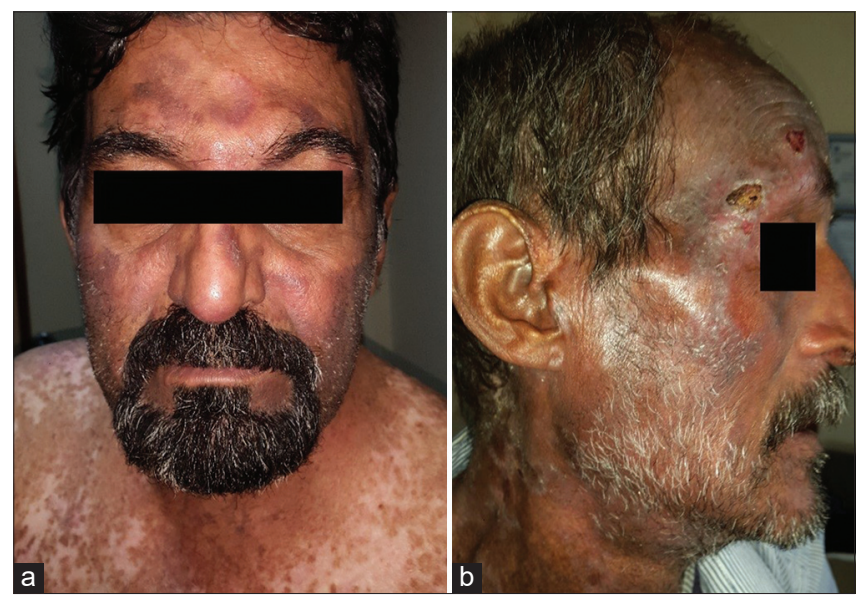

Figure 2: (a) 52-year-old male patient with poikilodermatous hypo pigmented changes over the trunk in addition to hyperpigmented patches on the face, (b) 67 year old male patient with ulcerated lesions associated with hyperpigmented patches of mycosis fungoides.

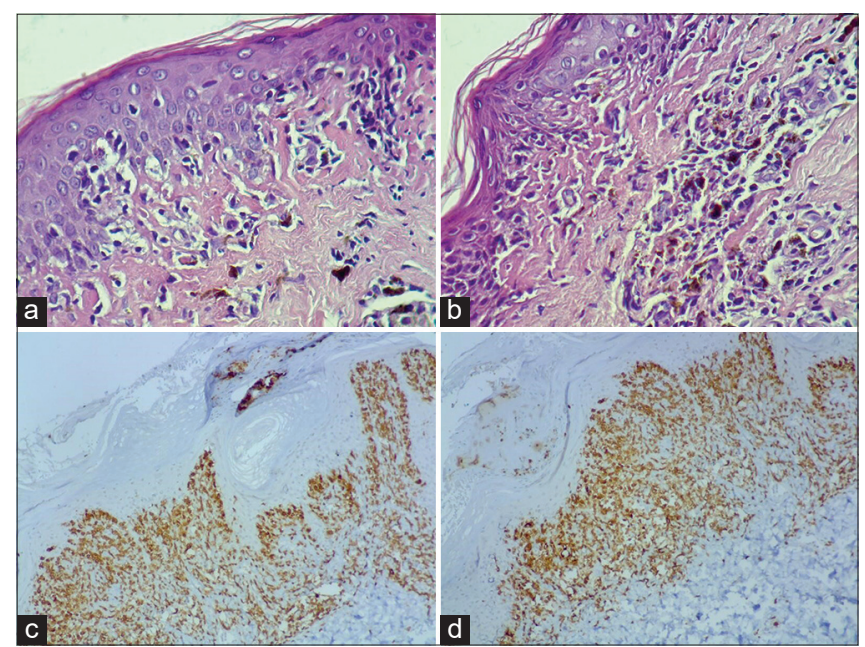

Figure 3: $(\mathrm{a}$ and $\mathrm{b}) \mathrm{H}$ and $\mathrm{E}$ stain $\times 400$ microscopic view showing epidermis with lymphocytic invasion and dermoepidermal damage. Also superficial and deep perivascular infiltrate in dermis with obvious melanin incontinence. (c and d) $\times 100$ Immunohistochemical staining was positive for CD4 and CD8 respectively.
CD4 and CD8 while negative for CD20 and CD30 (Figs. $3 \mathrm{c}$ and $3 \mathrm{~d}$ ). The other patient was positive for CD3 and CD4 while negative for CD8 and CD20.

\section{DISCUSSION}

Mycosis fungoides is the most common cutaneous T-cell lymphoma (CTCL) that in addition to its classic presentation of patches, plaques and tumors, may show atypical features defining many clinical variants of the disease. In Iraq, MF was very rare before 1980 and since then cases are increasing and this is well established by Iraqi studies where depleted uranium was incriminated $[15,16]$. So after many years of wars, new and unusual variants started to reveal themselves where hyperpigmented lichenoid MF is one of these rare variants.

Hyper pigmented MF is an uncommon, clinical variant of $\mathrm{MF}$, with a predilection for dark-skinned people [11]. In this study, we described the clinicopathological features of 12 patients with hyperpigmented MF. Fifty percent of patients were of younger age mainly in the $20 y-40 y$ hence their ages seem to be younger than classic MF with mean of 47 years versus 49.92 years mentioned previously in Iraqi studies [15].

Similar to the previously mentioned reports of hyperpigmented MF [5-14], all of the 12 patients, in the present study, were dark-skinned with Fitzpatrick skin type III and IV.

Acquired Cutaneous hyperpigmentations are frequent and have a long list of differential diagnoses as a consequence of skin problems, systemic diseases or secondary to environmental factors. Many common dermatoses, such as melasma, post-inflammatory hyperpigmentation, phytophotodermatoses, erythema dyschromicum perstans, cervical poikiloderma (Poikiloderma of Civatte), cutaneous amyloidosis, drug eruption and contact dermatitis, may present with hyperpigmented lesions [17].

This will impose a diagnostic challenge and probably preventing early recognition and management of hyperpigmented MF as many patients were misdiagnosed and maltreated for years. One of the most important cause of hyperpigmentaion in Iraqi population and neiboring countries is frictional melanosis over bony prominences so called lifa disease which is disease of maily young females that present with prominent dark pigmentation typically 
around the neck as a rippled pigmentaton,upper back,extensor surfaces of upper limbs and legs. While hsitopathology showed mainly dermal melanosis [18]. Accordingly this disease might be confused with early pigmented MF.

Therefore, patients with suspected hyperpigmented MF require repeated biopsies from several lesions to reach the final diagnosis. Hyperpigmented lesions may be the only manifestation of the disease or may be associated with other unusual variants as observed in five cases of present work, they were presented with poikilodermatous patches in addition to areas of hyperpigmented lesions, and poikilodermatous with ulceration in one patient. One patient had classic MF lesions in association with hyperpigmented MF. This is another finding that was consistent with the previous reports, where ichthyosiform plaques, poikiloderma, and ecthyma gangrenosum were observed in addition to the hyperpigmented MF $[7,8,10]$.

In all twelve patients, interface dermatitis with melanin incontinence were seen on hematoxylineosin staining, in addition to epidermotropism and dermal infiltrate of lymphocytes. Of notice some cases, the histopathology might be more pigmented lichenoid than the clinical picture and vice versa. This histopathological picture is consistent with what was previously reported of hyperpigmented MF $[5,7,8,10,11]$.

\section{CONCLUSION}

Hyperpigmented lichenoid MF is a rare clinical variant of cutaneous T-cell lymphoma, occurring mostly in patients with a dark complexion while it account for $11 \%$ in the present study. The histopathology of this variant showed marked dermal melanosis with basal epidermal damage. Hyperpigmented lesions may be the sole manifestation or it may coexist with other MF variants. Shedding light on this seemingly benign variant will aid in the early diagnosis and proper treatment. Hyperpigmented MF should be included in the long list of differential diagnosis of hyperpigmented skin dermatoses.

\section{Statement of Human and Animal Rights}

All procedures followed were in accordance with the ethical standards of the responsible committee on human experimentation (institutional and national) and with the Helsinki Declaration of 1975, as revised in 2008 .

\section{Statement of Informed Consent}

Informed consent was obtained from all patients for being included in the study.

\section{REFERENCES}

1. Yamashita T, Abbade LP, Marques ME, Marques SA. Mycosis fungoides and Sézary syndrome: clinical, histopathological and immunohistochemical review and update. An Bras Dermatol. 2012;87:817-30.

2. Sharquie KE, Al-Jaralla FA. Methotrexate in low split dose as a first line treatment option in the management of early mycosis fungoides. Am J Dermatol Venereol. 2019;8:95-8.

3. Pavlovsky L, Mimouni D, Amitay-Laish I, Feinmesser M, David M, Hodak E. Hyperpigmented mycosis fungoides: An unusual variant of cutaneous T-cell lymphoma with a frequent CD8+ phenotype. J Am Acad Dermatol. 2012;67:69-75.

4. Jawed SI, Myskowski PL, Horwitz S, Moskowitz A, Ouerfeld C. Primary cutaneous T-cell lymphoma (mycosis fungoides and Sézary syndrome). J Am Acad Dermatol. 2014;70:205.e1-205.e16.

5. Kikuchi A, Shimizu H, Nishikawa T. Mycosis fungoides with Marked Hyperpigmentation. Dermatology. 1996;192:360-3.

6. Yamamoto T, Katayama I, Nishioka K. Increased serum level of stem cell factor in association with disease progression of hyperpigmented mycosis fungoides. Br J Dermatol. 1999; 140:765-6.

7. Erbil H, Sezer E, Koseoglu D, Filiz N, Kurumlu Z, Bülent Taştan H, et al. Hyperpigmented mycosis fungoides: a case report. J Eur Acad Dermatol Venereol. 2007;21:982-3.

8. Pavlovsky L, Mimouni D, Amitay-Laish I, Feinmesser M, David M, Hodak E. Hyperpigmented mycosis fungoides: An unusual variant of cutaneous T-cell lymphoma with a frequent CD8+ phenotype. J Am Acad Dermatol. 2012;67:69-75.

9. Soughi M, Mernissi FZ. Hyperpigmented mycosis fungoides: a rare variant. Pan African Med J. 2013;15:13.

10. Pai VV, Kikkeri NN, Athanikar SC, Rai V, Dinesh US. Hyperpigmented mycosis fungoides with ecthyma gangrenosum. Indian J Cancer. 2015;52:79-80.

11. Jovic A, Gulin SJ, Rados J, Ceovic R, Ilic I, Marinovic B. Mycosis fungoides: A rare entity. J Am Acad Dermatol. 2017;76:AB160.

12. $\mathrm{Lu} \mathrm{YY,} \mathrm{Wu} \mathrm{CH}$, Lu CC, Hong $\mathrm{CH}$. Hyperpigmentation as a peculiar presentation of mycosis fungoides. An Bras Dermatol. 2017;92(5 Suppl 1):92-4.

13. Sankalp S, Sharad B, Arti S, Priyanka B, Niharika B. A case of cutaneous T-cell lymphoma (CD 8+) with multiple lesions treated with definitive radiotherapy. Iraq J Hematol. 2018;2:93-6.

14. Borowska K, Wasyłyszyn T. Mycosis fungoides as casus pro diagnosi. Our Dermatol Online. 2017;8:229-30.

15. Al-Hamamy H, Sharquie K, Noaimi A, Abdulwahhab W. Mycosis fungoides in iraqi patients-clinical, histopathological and immunohistochemical study. J Cosmet Dermatol Scien Applicat. 2015;05:116-24.

16. Ali AN. Mycosis fungoides in iraqi patients a clinical and histopathological study. a thesis submitted to iraqi board for medical specializations. Dermatol Venereol. 1999.

17. Cestari TF, Dantas LP, Boza JC. Acquired hyperpigmentations. An Bras Dermatol. 2014;89:11-25.

18. Sharquie KE, Al-Drky MK. Frictional dermal melanosis (lifa disease) over bony prominences. J Dermatol. 2001;28:12-5.

Copyright by Khalifa E. Sharquie, et al. This is an open access article distributed under the terms of the Creative Commons Attribution License, which permits unrestricted use, distribution, and reproduction in any medium, provided the original author and source are credited.

Source of Support: Nil, Conflict of Interest: None declared. 